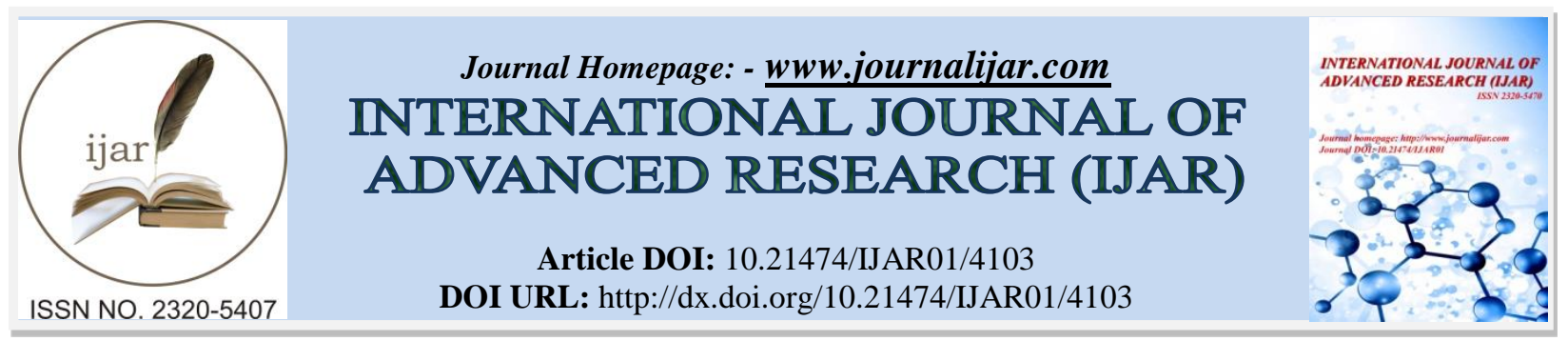

RESEARCH ARTICLE

\title{
ASSESSMENT OF EFFECT OF RICE HUSK ASH ON BURNT PROPERTIES OF BADEGGI CLAY.
}

\author{
O. Peter ${ }^{1}$, M. S. Abolarin ${ }^{2}$ and F. O. Anafi' ${ }^{2}$. \\ 1. Department of Mechanical Engineering, Kampala International University, Uganda. \\ 2. Department of Mechanical Engineering, Ahmadu Bello University, Zaria -Kaduna. Nigeria.
}

\section{Manuscript Info}

Manuscript History

Received: 07 March 2017

Final Accepted: 12 April 2017

Published: May 2017

Key words:-

Mineralogical analysis; clay; Rice husk ash; burnt properties.

\section{Abstract}

The effect of Rice Husk Ash (RHA) on the burnt property of clay (Badeggi) in Gbako Local Government Area of Niger Sate, Nigeria has been evaluated. $0 \%$ to $15 \%$ weight proportion of Rice Husk Ash (RHA) blended with clay were prepared for the basis of this analyses. $\mathrm{X}$-ray diffractometer (XRD) and X-ray florescence spectrometer (XRF) were used to determine the mineralogical and chemical constituent of the clay and RHA respectively. Plasticity of the clay, apparent porosity, bulk density, linear shrinkage, thermal shock resistivity, compressive strength, hardness, refractoriness and resistance to chemical attacks of the clay, and clay - RHA blends were analysed. The XRD analysis indicated that the clay was mainly Albite, with sufficient amount of Illite minerals. Result of chemical analysis indicated silica $\left(\mathrm{SiO}_{2}\right) 53.50 \%$ and alumina $\left(\mathrm{Al}_{2} \mathrm{O}_{3}\right) 28.70 \%$ to be main constituents of the clay. $\mathrm{SiO}_{2}$ content in the RHA was highest at $89.72 \%$ while other oxides were found in traces. Physical and mechanical property test confirmed that the inclusion of RHA in the clay resulted to considerable improvement in some properties and is beneficial for ceramic ware production.

Copy Right, IJAR, 2016,. All rights reserved.

\section{Introduction:-}

Clay is defined as earth or soil that is plastic and tenacious when moist and becomes permanently hard when baked or fired. It consists of a group of hydrous Aluminosilicate minerals formed by the weathering of feldspathic rocks, such as granite. Common clay is a mixture of kaolin (hydrated clay), and the fine powder of some feldspathic mineral that is anhydrous (without water) and not decomposed [1]

Innovation in proper management of agricultural wastes, continuous to pose a serious challenge. Nonetheless, recent trends favour the utilization of such biomass for value added purposes of fulfilling need in areas like renewable energy, fibre composites and textiles, food alternatives, organic manure and livestock feeds [2]. Refractory supplies to industries in Nigeria have become strict, while other times, delivery promises are often extended well beyond twelve months from placement of orders. This is due to changing competitive structure of the import-export trade, and quantitative restrictions on importation created by government policies and tight supplies of refractory materials threaten the future growth of industries in Nigeria [3]. Therefore, the development of local resources such as clay and rice husk $(\mathrm{RH})$, for production industries in Nigeria, justified by the need to meet technological requirements, incline further research into clay deposits. Rice husk ash (RHA) is which is a product obtained from the burning of rice husk. As such, the husk is a by-product of the rice milling industry. By weight, $10 \%$ of the rice grain is rice 
husk, and upon burning the rice husk, about $20 \%$ becomes RHA. Nonetheless, the choice and sustainability of a particular material are largely based on its availability, type of the project, individual preference, durability, proximity and economic consideration [4].

This study is a contribution to increasing demand for alternative materials with low weight, high strength, increased hardness and prolonged service life, and material recycling. While all the necessary raw materials required for the manufacture of refractory/ceramics products are: binders and clay which are available in large quantities here in Nigeria plus the good investment opportunity for the production of ceramics locally, there are not enough firm or government support programs to explore the abundance of these resources.

\section{Materials and Method:-}

Clay samples used are collected from the excavation site, the same location is popular for local dwellers who obtain clay for their pottery practices, near to the bank of Badeggi river in Gbako LGA \{location - 09 $05^{\prime} \mathrm{N}$ and $06^{0} 15^{\prime} \mathrm{E}$ \} of Niger State Nigeria. Rice husk from National Cereal Research Institute (NCRI) near Badeggi community, dried in open air for five (5) days, burnt to char and heat treated (Soaked) in an electric furnace but not exceeding $700{ }^{\circ} \mathrm{C}$ until the char turns into a grew - whitish appearance resembling ashes. The mixture proportion of RHA to clay used was within $15 \%$ RHA to $85 \%$ dry clay by weight. The ground-up clay was sieved using an ASTM standard sieve of aperture sizes for Coarse $(75 \mu \mathrm{m})$, Medium $(200 \mu \mathrm{m})$ and Fine $(600 \mu \mathrm{m})$. Any aggregates retained on the $75 \mu \mathrm{m}$ sieve were rejected as too coarse. The three aggregates obtained from sieving were homogenously mixed and with the corresponding percentages by weight in rice husk ash $(5 \%, 10 \%$, and 15\%) shown in Table 1 until the required proportion met.

Water was gently added by spraying over the mixtures until the paste formed. The molds were then cut from the successive paste samples and compressed using a hydraulic press machine up to a pressure of $300 \mathrm{KN} / \mathrm{m}^{2}$. Shapes of the following dimensions were molded; square samples of $25.4 \mathrm{~mm}$ for the compressive test, $50 \times 50 \times 40 \mathrm{~mm}$ samples for linear shrinkage, apparent porosity, bulk density and thermal shock resistance, and $78 \times 50 \times 25 \mathrm{~mm}$ shaped samples for hardness and chemical resistance test. The specimen samples were dried at $110^{\circ} \mathrm{C}$ for up to $24 \mathrm{hrs}$ and then cooled [5], before calcination (firing to $1200^{\circ} \mathrm{C}$ ). The firing was done gradually at controlled firing rate over four firing stages [6]. This procedure is repeated for the batch composition of each clay sample.

Table 1:- Blend proportion of clay - rice husk ash

\begin{tabular}{|c|c|c|c|}
\hline \multicolumn{2}{|c|}{ S/No } & \multicolumn{2}{|c|}{ Batch composition (\% wt.) } \\
\cline { 3 - 4 } & & Clay & Rice Husk Ash \\
\hline 1 & A & 100 & 0 \\
\hline 2 & B & 95 & 5 \\
\hline 3 & C & 90 & 10 \\
\hline 4 & D & 85 & 15 \\
\hline
\end{tabular}

\section{Chemical and Mineralogical Analysis:-}

The elemental composition of the clay and RHA was determined using an Energy Dispersion X-ray Fluorescence Spectrometer (ED-XRF), Mini Park X - 4 model, located at Defence Industry Corporation of Nigeria (DICON). The mineralogical constituent of the clay was also determined by an X-ray Diffractometer (XRD), Shimadxu XRD-6000 model, available at National Steel Raw Materials \& Exploration Agency (NSRMEA) in Nigeria. The XRD was Operated with $\mathrm{CuK}_{\bar{\alpha}}$ radiation $(\lambda=1.5418 \AA)$ at $40 \mathrm{Kv} / 30 \mathrm{~mA}$ from $0^{\circ}<2 \theta<60^{\circ}$.

\section{Physical Analysis:-}

Plasticity Index: Plasticity limit of the clay was determined by an atterberg limits test using the Casagrande Apparatus and accessories. The moisture contents for the clay was identified and the liquid limit (LL) and plastic limit (PL) tests results were used to compute the plasticity index, PI. The difference between the LL and PL gave the PI for each of the clays, following same procedure as [7]

Apparent Porosity: The dry weight of the specimen after it has been heated in an oven up to $110^{\circ} \mathrm{C}$ and then cooled was recorded as 'Dw.' The dried specimen were suspended freely in distilled water, allowed to boil for up to one (1) hour while consistently shaking to release trapped air bubbles, then cooled to room temperature and differential weights (suspended weight) denoted as ' $S$ ' were recorded. The specimen was removed from the water, wiped dry from dripping water so that the new soaked weight (saturated weight) was registered as 'W.' 


$\begin{aligned} & \text { Apparent }=\frac{\text { Volume of Water Absorbed After Boiling }}{\text { Bulk Volume }} \times 100 \% \\ & \text { Porosity (\%) }\end{aligned}$
\[ =\frac{\mathrm{W}-\mathrm{Dw}}{\mathrm{W}-\mathrm{S}} \times 100 \% \]

Bulk Density: The bulk density was determined using parameters obtained from the analyses of apparent porosity, by considering density factor of water (Equation 2) and was used to calculate bulk density of the samples.

Bulk Density $\left(\mathrm{mg} / \mathrm{m}^{3}\right)=\frac{\text { True Weight }}{\text { Bulk Volume }} \quad \times \rho$

$$
=\frac{\mathrm{Dw}}{\mathrm{W}-\mathrm{S}} \times \rho
$$

To further understand the effect of Rice Husk Ash inclusion in clay, a total of twelve (12) samples of the batch compositions were obtained on the corresponding 5, 10, and 15\% weight proportion of RHA for clay in fine, medium and coarse sieve size.

Linear Shrinkage: The diagonal sides of the samples $(50 \mathrm{~mm} \times 50 \mathrm{~mm} \times 40 \mathrm{~mm})$ were marked after air drying for 3hours then fired to $1200^{\circ} \mathrm{C}$, the marked diagonal length was re-measured again to compute the linear shrinkages. Their Linear shrinkages were determined using the relationship $\Delta \mathrm{L} / \mathrm{L}$

Compressive Strength: Varying loads were applied at a uniform rate until the tests specimen failed to support the load, Average strength value was computed to the nearest $0.01 \mathrm{MN} / \mathrm{m}^{2}$, [5] formulae:

Compressive Strength $=\frac{W o}{\text { Ao }}$

$\mathrm{W}_{\mathrm{o}}=$ maximum load $(\mathrm{KN})$,

$\mathrm{A}_{\mathrm{o}}=$ Average areas of the upper and lower bearing surface of specimen $\left(\mathrm{mm}^{2}\right)$,

Surface Hardness: The Surface Hardness test was carried out using a superficial Rockwell hardness tester, (Steel ball indenter) where 130 represents zero penetration

$$
\mathrm{HRN}=\mathrm{E}-\mathrm{e}
$$

HRN = Rockwell hardness number.

$\mathrm{E}=\mathrm{A}$ constant depending on the form of the indenter, which is 130 units.

$\mathrm{e}=$ Permanent increase in depth of penetration due to major load $(\mu \mathrm{m})$.

Thermal Shock Resistance: The samples after heating in a resistance box of an electric furnace maintained to $1200^{\circ} \mathrm{C}$ and soaked for 15 minutes, were cool for 15 min and observed for any cracks. When none is visible, the samples are returned to the furnace, and the same process repeated until cracks appear. Thermal shock resistance was recorded as the number of cycles before there is a crack on the sample.

Resistance to Chemical Attacks (Resistance to Erosive Corrosion): This test was carried out following the ASTM C67: Opposite ends of the sample specimen, $78 \mathrm{~mm} \times 50 \mathrm{~mm} \times 25 \mathrm{~mm}$ batch composition were submerged up to a minimum depth of $1 \frac{1}{2}$ inch. (38.1mm) In a $10 \%$ solution of hydrochloric acid (HCL) for 3 hr. The opposite end portion of the same specimen also submerged in a similar solution of potassium hydroxide (KOH) for 3 hours while maintaining the temperature at $15-27^{\circ} \mathrm{C}$. 
Refractoriness: The Pyrometric Cone Equivalent (P.C.E) equipment was used to estimate the refractoriness of the clay in pure and blended form. In other to determine the P.C.E, batch samples were pulverized using the number 60 mesh and then formed into rectangular test blocks. The molded blocks (Batch A, B, C, D in their proportions) were mounted each one after the other on an inert refractory disc then transferred into the furnace. Ensuring that the vertical edges of the cone designed to deform at $1300^{\circ} \mathrm{C}, 1400^{\circ} \mathrm{C}, 1600^{\circ} \mathrm{C}$ were maintained in an upright position before heating at the rate of $10^{\circ} \mathrm{C} /$ minute in the P.C.E furnace. The softening of the block samples were determined by comparing them with that of standard pyramid cones (Segar Cones).

\section{Results and Discussions:-}

The XRD pattern presented in Figure 1. Shows the clay to have its highest peak intensity of Albite mineral at 3300 on position 24.1, 2Theta (deg) as seen in Table 2 being the most dominant mineral. Others were Lizard and Illite [Magnesium Iron Silicate Hydroxide- $\left(\left(\mathrm{Mg}, \mathrm{Fe}_{3} \mathrm{Si}_{2} \mathrm{O}_{5}(\mathrm{OH})_{4}\right)\right.$ ] \& [Potassium Aluminum Silicate Hydroxide- $((\mathrm{K}$, $\left.\left.\mathrm{H}_{3} \mathrm{O}\right) \mathrm{Al}_{2} \mathrm{Si}_{3} \mathrm{AlO}_{10}(\mathrm{OH})_{2}\right)$ ], appearing at 23.9 and 47.6, (2-Theta (deg)) positions respectively.

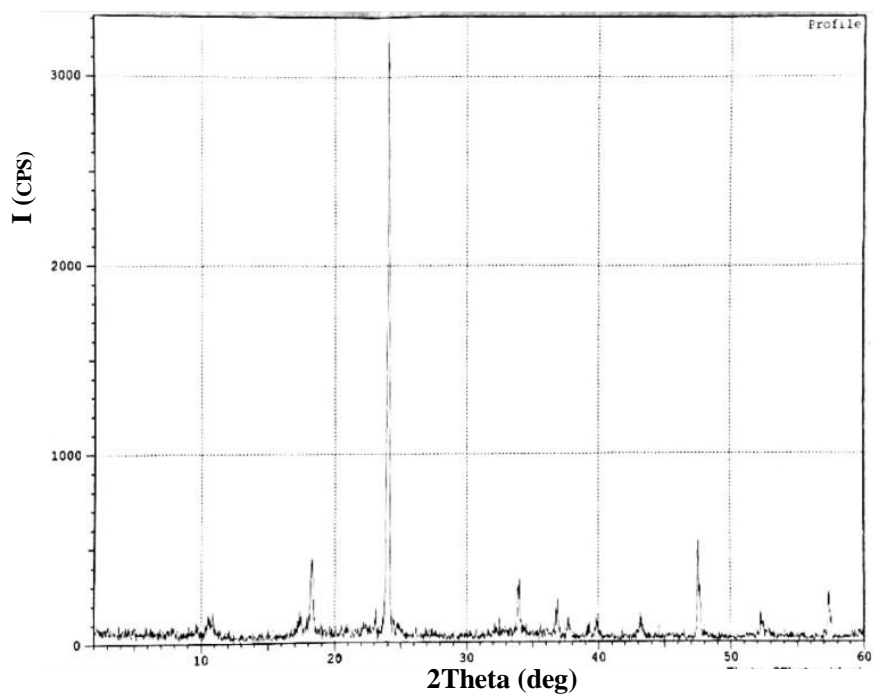

Fig. 1:- X-ray diffraction pattern for Badeggi clay

Table 2:- Showing the d-spacing, relative intensities and count (hkl) of Badeggi clay powder

\begin{tabular}{|c|c|c|c|}
\hline 2-Theta & $\mathbf{d}(\mathbf{\AA})$ & Intensity & $\boldsymbol{h k l}$ \\
\hline 18.3077 & 4.8420 & 11 & 33 \\
\hline 23.1414 & 3.8404 & 3 & 10 \\
\hline 23.9531 & 3.7120 & 31 & 93 \\
\hline 24.1031 & 3.6893 & 100 & 299 \\
\hline 24.4978 & 3.6307 & 3 & 27 \\
\hline 33.9655 & 2.6373 & 9 & 16 \\
\hline 36.9105 & 2.4333 & 5 & 9 \\
\hline 37.7421 & 2.3816 & 3 & 9 \\
\hline 39.8606 & 2.2597 & 20 & 59 \\
\hline 47.5758 & 1.9075 & 3 & 10 \\
\hline 52.3072 & 1.7476 & 9 & 28 \\
\hline 57.3804 & 1.6045 & & \\
\hline
\end{tabular}


The chemical composition of the clay and RHA presented in oxides form, shown in Table 3 Indicates high silica content for both samples. Iron content of $11.26 \%$ in the clay was sufficient to develop a reddish color observed in the fired molds while the significantly high amount of silica $89.72 \%$ confirms an excellent pozzolanic agent, as this value exceed the $70 \%$ minimum for Class ' $F$ ' pozzolan reported by [8].

Table 3:- Chemical Composition of Clay and Rice Husk Ash (RHA)

\begin{tabular}{|c|c|c|}
\hline Compound & Badeggi Clay & Rice Husk Ash \\
\hline $\mathrm{Al}_{2} \mathrm{O}_{3}$ & 28.7 & 1.9 \\
\hline $\mathrm{SiO}_{2}$ & 53.5 & 89.72 \\
\hline $\mathrm{K}_{2} \mathrm{O}$ & 1.42 & 1.29 \\
\hline $\mathrm{CaO}$ & 0.717 & 0.01 \\
\hline $\mathrm{TiO}_{2}$ & 2.07 & 0.01 \\
\hline $\mathrm{V}_{2} \mathrm{O}_{5}$ & 0.11 & 0.01 \\
\hline $\mathrm{Cr}_{2} \mathrm{O}_{3}$ & 0.03 & 0.01 \\
\hline $\mathrm{MnO}$ & 0.17 & 1.27 \\
\hline $\mathrm{Fe}_{2} \mathrm{O}_{3}$ & 11.26 & 0.01 \\
\hline $\mathrm{NiO}_{\mathrm{CuO}}$ & 0.003 & 1.14 \\
\hline $\mathrm{ZnO}$ & 0.019 & 0.17 \\
\hline $\mathrm{Ga}_{2} \mathrm{O}_{3}$ & 0.01 & - \\
\hline $\mathrm{Ag}_{2} \mathrm{O}$ & 0.005 & - \\
\hline $\mathrm{Eu}_{2} \mathrm{O}_{3}$ & 1.58 & - \\
\hline $\mathrm{Yb}_{2} \mathrm{O}_{3}$ & 0.20 & - \\
\hline $\mathrm{Re}_{2} \mathrm{O}_{7}$ & 0.20 & 0.2 \\
\hline $\mathrm{IrO}_{2}$ & 0.07 & - \\
\hline $\mathrm{MoO}_{3}$ & 0.13 & 0.88 \\
\hline $\mathrm{Cl}$ & - & 0.98 \\
\hline
\end{tabular}

Plasticity Index: Results of Atterberg limit test for Badeggi clay shown in Table 4, imply that more inert additives could be accommodated for molding purposes and bests other clays by various researchers. Naogaon - Bangladesh clay with a plasticity index of $13 \%$, by [9], Ibaji clay with $20.1 \%$ plasticity by [4] and Oboro clay $23 \%$ as reported by [7]. Their values all fall below the plasticity index of Badeggi Clay, corresponding to 46\% Liquid limit, shown in Figure 2.

Table 4:- Plasticity Index of Badeggi clay

\begin{tabular}{|c|c|c|c|}
\hline Description & $\begin{array}{c}\text { Liquid Limit } \\
\left(\boldsymbol{\%} \mathbf{L L}_{\mathbf{L}}\right)\end{array}$ & $\begin{array}{c}\text { Plastic Limit } \\
\left(\boldsymbol{\%} \mathbf{P}_{\mathbf{L}}\right)\end{array}$ & $\begin{array}{c}\text { Plasticity Index } \\
\left(\mathbf{L}_{\mathbf{L}}-\mathbf{P}_{\mathbf{L}}\right)\end{array}$ \\
\hline Badeggi Clay & 46 & 18 & 28 \\
\hline
\end{tabular}

Apparent Porosity: The parameter of apparent porosity for the batch composition (Sample A, B, C \& D) are presented in Table 5, ranged from $15.06 \%$ to $20.47 \%$ and with the clay sample (without additive) having the highest porosity value. These is as a result of inconsistency in grain sizes, between the clay particles and RHA. These pore spaces would have disappeared as a consequence of the interlocking synergy of the RHA to fill-in and eliminate the pore spaces within the clay during the forming process. 


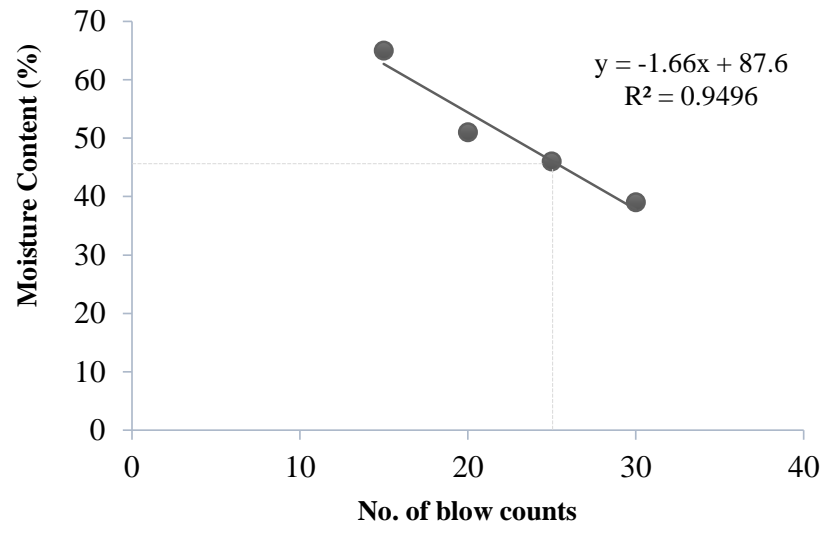

Fig. 2:-Liquid Limit Flow Curve for Badeggi clay.

Table 5:- Plasticity Index of Badeggi clay

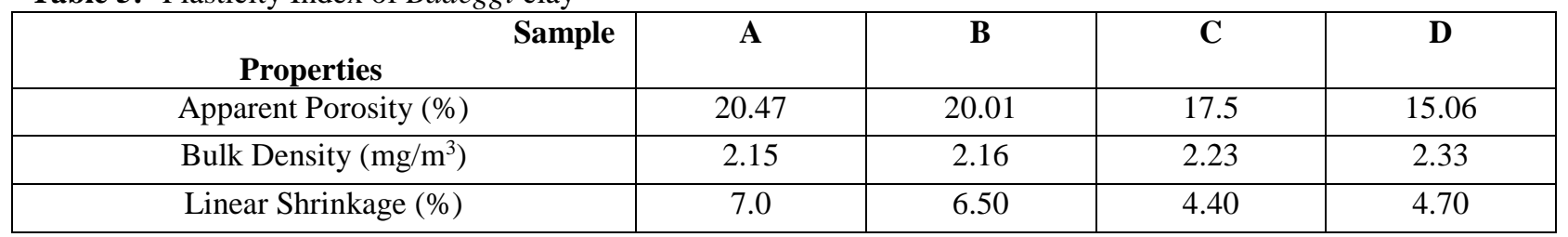

Bulk Density: The bulk density of the batch compositions continued to increase as the weight proportion of clay in the samples increased (Table 5). Average bulk densities of 2.15, 2.16, 2.23 and $2.33 \mathrm{mg} / \mathrm{m}^{3}$ were obtained from the homogeneously mixed aggregates of the batch composition. The values are closely matched with the ASTM C: 20 (2002) recommendations of $2.24 \mathrm{mg} / \mathrm{m}^{3}$ to $2.3 \mathrm{mg} / \mathrm{m}^{3}$. However, it was observed as shown in Figure 3 , the continuous inclusion of rice husk ash up to $15 \%$ weight proportion in the coarse clay $(75 \mu \mathrm{m})$ sample, offered higher bulk density compared to the fine and medium sieve aggregates of $600 \mu \mathrm{m}$ and $200 \mu \mathrm{m}$ samples respectively.

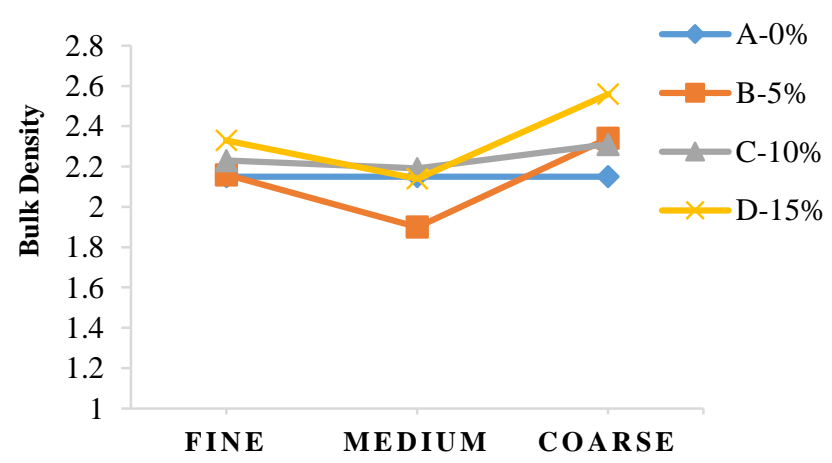

Fig.3:- Effect of increasing \%-weight-proportion of RHA on Bulk Density Property of clay of different sieve sizes.

Linear Shrinkage: The linear firing shrinkages of the clay and RHA samples presented in Table 5 infer that the more the inclusion of RHA the lesser the shrinkage value within $0 \%$ and $10 \%$ wt of RHA. The addition of RHA to Badeggi clay up to $15 \%$ proportion by weight could still be more stable than the clay solely as crack propagation were significantly reduced in the RHA blended samples. 
Table 6:- Plasticity Index of Badeggi clay

\begin{tabular}{|c|c|c|c|c|}
\hline Details & A & B & C & D \\
\hline Thermal Shock Resistance & 22 & 15 & 27 & $33^{+}$ \\
\hline Pyrometric Cone Number & 17 & 17 & 17 & 17 \\
\hline Compressive Strength (Mpa) & 17.77 & 20.51 & 19.02 & 15.20 \\
\hline Hardness (R45N) & 70.10 & 71.80 & 71.50 & 79.50 \\
\hline
\end{tabular}

Compressive Strength: The compressive strength for all fired sample showed compressive strength between $15.20 \mathrm{MN} / \mathrm{m}^{2}$ to $20.51 \mathrm{MN} / \mathrm{m}^{2}$ Table 6 . The result illustrates an increase in compressive strength of the fired sample from $17.77 \mathrm{MN} / \mathrm{m}^{2}$ at $0 \%$ to $20.51 \mathrm{MN} / \mathrm{m}^{2}$ at $5 \%$ wt of RHA. These could be due to sintering temperature with regards to the amount of RHA in the clay and the maximum time of heating the samples as further reduction of strength is observed at $10 \%$ and $15 \%$.

Surface Hardness: On the Rockwell superficial hardness tester, depth of penetration decreased as load increased for masses $15 \mathrm{~kg}, 30 \mathrm{~kg}$, and $45 \mathrm{~kg}$ proportionately through all the samples. Very small significant difference was observed on penetration of the samples, seen in Figure 4. The Rockwell Hardness Number for $45 \mathrm{KgF}$ is shown in Table 6 with the lowest penetration recorded in the sample which has the most inclusion of RHA of $15 \%$ and may be attributed to the increase in density and decrease in porosity leading to the elimination of pore spaces liable to be compressed under load.

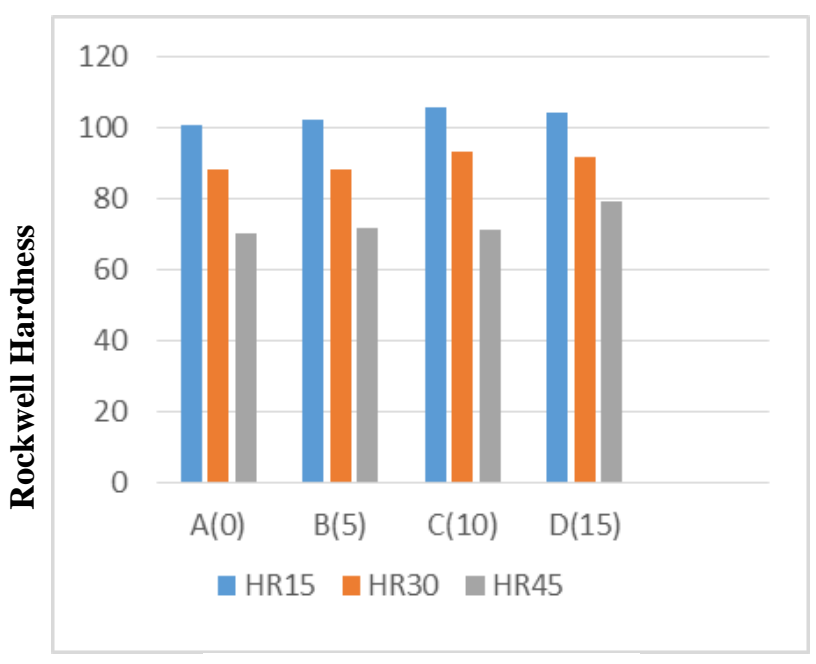

RHA Content (wt. \%)

Fig. 4:- Liquid Limit Flow Curve for Badeggi clay.

Thermal Shock Resistance: The number of the cycle before failure for Badeggi clay at $0 \%$ wt proportion of RHA endured up to 22 cycles while at 5\% and $10 \%$ was seen visible cracks and correspond with 15 and 27 cycles respectively, shown in Table 6 . At $1000^{\circ} \mathrm{C}$ of heating up to 33 cycles, sample ' $\mathrm{D}$ ' remained unaffected, with no visible cracks. These could be due to increased amount of silica composition from the RHA as it increased in weight proportion for the batch composition, and offers more pozzolanic characteristics, therefore offers more stability to repeated heating and cooling.

Pyrometric Cone Equivalent (Refractoriness): The softening point (temperature) and the corresponding pyrometric cone equivalents of the batch composition presented in Table 6 infer that neither of the batch composition with RHA inclusion soften (They retain their original shapes) after heating up to $1500^{\circ} \mathrm{C}$ (PCE 23). However, the raw clay ( $0 \%$ wt proportion of RHA) soften after heating up to $1450^{\circ} \mathrm{C}$.

Resistance to Chemical Attack: No obvious difference (Color change, swelling/dissolution in the liquid medium, or fumes emission) was noticed in the dilute Acid-Base deep test. 


\section{Concussion:-}

The mineralogical composition of Badeggi clay consists largely of Albite and Illite clay structures. The XFR analysis also indicates silicon to aluminum ratio of about 2:1 for the clay, while the high Silica content of $89.72 \%$ in the RHA is suggested for use as local sources of artificial pozzolana.

Evaluation of physical and mechanical properties of the samples revealed that for best engineering properties and applications, the inclusion of Rice Husk Ash (RHA) up to $15 \%$ wt proportion and firing temperature of $1200^{\circ} \mathrm{C}$ performed satisfactorily. The value of plasticity index at $0 \%$ was found to be $28 \%$. However, moisture content increased and so did the compaction potential of the clay, resulting to a rather insignificant change in density but reduced the porosity of the batch compositions. The addition of RHA lowered the shrinkage tendency by $39 \%$ indicating a reduction of risk to defects like warping and cracking when heated.

Other Mechanical Characteristics of the clay batch compositions which were improved are thermal shock resistance, compressive strength, and surface hardness. The clay batch composition showed the neutral effect to slag attack, while on the refractoriness; it is greater than, but not limited to $1450^{\circ} \mathrm{C}$ when reinforced with rice husk ash. Characterisation of Badeggi clay has been experimented and hold lots of potential for ceramic application, the use of agricultural waste also, combined with the clay to improve mechanical property has proven successful and recommended for use in ceramic production.

\section{References:-}

1. S. O. Adelabu, (2012). Documentation, Application and Utilisation of Clay Minerals in Kaduna State (Nigeria). INTECH. Pp. 3 - 20

2. R. O. Ibrahim and O. Peter, (2017). Untapped Wealth Potential in Fruit Wastes for Uganda Community", International journal of advanced academic research (IJAAR), ISSN: 2488-9849

3. M. M. Muhammadu, (2013). An Investigation on Refractory Clays Properties for Application in Metallurgical Industries in Nigeria. International Journal of Advanced Research, Volume 1, Issue 6, 200-207.

4. O. I. Agbede, and M. Joel, (2011). Effect of Rice Husk Ash (RHA) on the Properties of Ibaji Burnt Clay Bricks. American Journal of Scientific and Industrial Research, Pp674-677.

5. ASTM C 67: (2002) Standard Test Methods for Sampling and Testing Brick and Structural Clay Tile.

6. A. A. Jock, A. F. Ayeni, S. L. Jongs, and S. N. Kangpe, (2013). Development of Refractory Bricks from Nigerian Nafuta Clay Deposits. International Journal of Materials and Technologies. Vol.1, Pp189 - 195.

7. U. Mark, (2010). Characterization of Ibere and Oboro Clay Deposits in Abia State, Nigeria for Refractory Applications. International Journal of Natural and Applied Sciences, 6(3): 296-305.

8. K. Kartini, (2011) Rice Husk Ash - Pozzolanic Material for Sustainability, International Journal of Applied Science and Technology, 1(6), p. 169-178.

9. S. M. Sultana, I. M. Hossain, A. Rahman and H. M. Kahn, (2014). Influence of Rice Husk Ash and Fly ash on Properties of Red Clay. Journal of Science Research. 6 (3), Pp. 421 - 430. 